\title{
Evaluation of the role of staphylococci in the pathomechanism of conjunctivitis
}

\author{
Ewa Jasińska · Agnieszka Bogut • Agnieszka Magryś • Alina Olender
}

Received: 30 January 2021 / Accepted: 16 March 2021 / Published online: 28 March 2021

(C) The Author(s) 2021

\begin{abstract}
Purpose Determination of the association between ica genes and phenotypic biofilm formation in staphylococcal isolates involved in conjunctivitis, their antibiotic resistance as well as detection of selected virulence characteristics: adhesion to epithelial cells and in vitro cytotoxicity.

Methods The study included 26 Staphylococcus aureus (SA) and 26 Staphylococcus epidermidis (SE) isolates. The presence of icaAD genes and ica operon was determined by the PCR assay. Phenotypic biofilm formation was verified using the microtitre plate assay. Antibiotic resistance was performed using the disc diffusion method. Staphylococcal ability to attach to host cells was assessed by flow cytometry. Cytotoxicity on epithelial cells was evaluated by LDH assay.

Results The ica genes were detected in $26.9 \%$ of SE and in $42.3 \%$ of SA isolates. Only $15.3 \%$ of isolates (SE) were positive for both the icaAD and the ica operon. Phenotypically, $19.2 \%$ of SE isolates were strong biofilm producers, among which three were both icaAD- and ica operon-positive. About 26.9\% of
\end{abstract}

E. Jasińska

Department of General Ophthalmology, Medical

University of Lublin, Lublin, Poland

A. Bogut $(\varangle) \cdot$ A. Magryś $\cdot$ A. Olender

Chair and Department of Medical Microbiology, Medical

University of Lublin, Lublin, Poland

e-mail: agnieszkabogut@umlub.pl
SA isolates were strong biofilm producers. Methicillin resistance (MR) was detected in $34.6 \%$ of SE and $26.9 \%$ of SA isolates. About $75 \%$ of MR isolates were multidrug resistant. SA isolates adhered to host cells more extensively than SE. SA isolates released higher level of LDH than SE.

Conclusions Adherence abilities were commonly observed in staphylococci associated with conjunctivitis. However, low prevalence of isolates positive for a complete and functional ica locus and low prevalence of strong biofilm producers was detected. SA adhered to a greater extent to eukaryotic cells than SE and were more cytotoxic.

Keywords Staphylococcus - Conjunctivitis · Biofilm · Adhesion · Cytotoxicity assay · Drugresistance

\section{Introduction}

Staphylococcal species including Staphylococcus aureus (SA) and Staphylococcus epidermidis (SE) are among the most common bacterial pathogens involved in the aetiology of acute conjunctivitis [1].

Important aspects of pathogenic potential of staphylococci linked to their ability to cause conjunctivitis include initial adherence, inherent virulence, cytotoxicity, as well as evasion of the host immune 
system and antimicrobial tolerance/resistance facilitated by the biofilm production [2-4].

Adherence to host cells is a preliminary step necessary to initiate and establish infection. Staphylococci express a series of proteins/adhesins, such as the microbial surface components recognizing adhesive matrix molecules (MSCRAMMs) that bind fibrinogen, fibronectin, collagen, laminin and play a prominent role in the initial adhesion [5-7]. Once attachment to tissue is accomplished, staphylococcal biofilm is able to grow by proliferation and production of a scaffolding extracellular matrix. The important matrix components in the staphylococcal biofilm include the polysaccharide intercellular adhesin (PIA), extracellular DNA (eDNA), teichoic acids, and proteins $[8,9]$.

The PIA consisting of the poly- $\beta(1-6)-\mathrm{N}$-acetylglucosamine and encoded by the ica operon is regarded essential for the biofilm formation. In addition to bacterial aggregation and important structural functions in the biofilm matrix architecture and is implicated in bacterial adhesion to biomaterial surfaces as well as evasion from the host immune response. The ica locus consists of the icaADBC operon that contains four genes encoding proteins required for the generation of the PIA. The icaA and $i c a D$ are considered the principal genes involved in the synthesis of the exopolysaccharide. The product of the icaA gene is a transmembrane protein with $\mathrm{N}$-acetylglucosaminyl transferase activity necessary for the synthesis of the poly- $\mathrm{N}$-acetylglucosamine polymer. Protein encoded by the $i c a D$ gene, in turn, is considered essential for the most favourable enzymatic activity of the $i c a A$ gene product. Enzymatic activity of the icaA gene product becomes significant and olygomers longer than 20 residues are synthesized only when coexpressed with the icaD gene product [10].

Although PIA represents a major mechanism of the biofilm production both in SA and in SE, certain staphylococcal surface proteins can also promote the accumulation phase by the ica-independent mechanism. The cell wall anchored proteins mediate primary attachment but also promote intercellular adhesion, biofilm accumulation and maturation. This is subsequently followed by dispersal phase during which the biofilm structure is disrupted by enzymatic degradation of matrix components by proteases, nucleases, and a group of $\alpha$-helical peptides called phenol- soluble modulins (PSMs) functioning as surfactants $[8,10]$.

Although staphylococci are generally classified as extracellular bacteria, recent data revealed that these bacteria can invade various types of host cells, professional phagocytes and non-phagocytic cells, including fibroblasts, epithelial cells and others. Internalized bacteria can either induce host cell apoptosis or survive and persist intracellularly for several days $[5,7]$. The induction of host cell death has been linked with the ability of SA to secrete cytolytic toxins, such as $\alpha$-toxin or Panton-Valentine leucocidin (PVL) [6]. Unlike SA, which typically produces aggressive virulence determinants, commensal SE seems to possess a limited number of virulence factors, which rather promote its persistence, not invasive infections $[11,12]$.

The aim of the study was determination of the association of the ica genes with the phenotypic biofilm formation in staphylococcal isolates cultured from patients with conjunctivitis, analysis of the association regarding the ica gene detection, phenotypic biofilm production capacity and the antibiotic resistance profiles of the isolates as well as detection of selected virulence characteristics associated with adhesion to epithelial cells and cytotoxicity in the in vitro model (cell line Detroit 562).

\section{Materials and methods}

\section{Bacterial strains}

The study included a total of 52 staphylococcal isolates (26 SA isolates and $26 \mathrm{SE}$ isolates) cultured from 52 conjunctival swabs collected from patients demonstrating the clinical signs and symptoms of bacterial conjunctivitis. Each conjunctival swab was obtained from the lower fornix of each case and subsequently cultured onto the sheep blood agar and mannitol salt agar (MSA). The inoculated media were incubated at $37{ }^{\circ} \mathrm{C}$ for up to $48 \mathrm{~h}$. The identification of isolates growing in cultures was initiated with the use of conventional laboratory methods including Gram staining, catalase reaction, haemolytic activity on the sheep blood agar, growth on the mannitol salt agar (MSA), as well as the coagulase test. Final identification of the isolates to the species level was performed 
using the ID32 STAPH (BioMérieux) biochemical test according to the manufacturer's instructions.

Antimicrobial susceptibility

Susceptibility of staphylococcal isolates to antimicrobial drugs was evaluated using the disc diffusion method. The tests were performed and interpreted according to the current recommendations of the European Committee on Antimicrobial Susceptibility Testing (EUCAST). The tested antibiotics included the following: cefoxitin (FOX), erythromycin (E), clindamycin (CC), tetracycline (TE), norfloxacin (NOR), ciprofloxacin (CIP), ofloxacin (OFX), levofloxacin (LVX), moxifloxacin (MXF), gentamicin $(\mathrm{GM})$, amikacin $(\mathrm{AN})$, neomycin $(\mathrm{N})$, chloramphenicol (C), and co-trimoxazole (TMP/SXT).

\section{PCR detection of the ica genes}

\section{Bacterial DNA extraction}

Bacterial DNA for the PCR detection of the ica genes was isolated using the following procedure: staphylococcal colonies grown on the blood agar medium were collected with an inoculation loop and suspended in $150 \mu \mathrm{l}$ of water. The solution was incubated at $95^{\circ} \mathrm{C}$ for $10 \mathrm{~min}$ followed by $10 \mathrm{~min}$ incubation in an ultrasonic bath. The solution was then centrifuged for $5 \mathrm{~min}$ at a maximum speed, and the supernatant containing the DNA was transferred to a new tube and subsequently used for the PCR reaction.

PCR method for amplification of icaA and icaD genes

The primers were synthesized by Genomed (Poland).

For the detection of icaA, 5'-TCTCTTGCAGGAGCAATCAA was used as the forward primer, and 5'TCAGGCACTAACATCCAGCA was used as the reverse primer [9]. The two primers enabled to obtain a 188-bp amplification product.

For the detection of icaD, 5'-ATGGTCAAGCCCAGACAGAG was used as the forward primer, and 5'-CGTGTTTTCAACATTTAATGCAA was used as the reverse primer [9]. The two primers enabled to obtain a 198-bp amplification product.
The PCR reaction was conducted in a $50 \mu$ volume containing the above-mentioned primers $(1 \mu \mathrm{mol}$ each), together with the extracted bacterial DNA, $0.2 \mathrm{mM}$ of each of dATP, dCTP, dGTP, dDTP, $1.25 \mathrm{U}$ Dream Taq Polymerase, and 10X Dream Taq Buffer (Thermo Scientific).

A thermal profile of the reaction was as follows: incubation at $95{ }^{\circ} \mathrm{C}$ for $2 \mathrm{~min}$, followed by 35 cycles at $95{ }^{\circ} \mathrm{C}$ for $30 \mathrm{~s}$ (denaturation), $55^{\circ} \mathrm{C}$ for $30 \mathrm{~s}$ (annealing), $72{ }^{\circ} \mathrm{C}$ for $1 \mathrm{~min}$. (extension), and $72{ }^{\circ} \mathrm{C}$ for $10 \mathrm{~min}$. (final extension) after the 35 cycles.

After amplification, $10 \mu \mathrm{l}$ of the PCR mixture was analysed by agarose gel electrophoresis (2\% agarose in Tris-borate-EDTA). Molecular weight marker ФX174 DNA/BsuRI (HaeIII) Marker (Thermo Scientific) was used.

PCR method for amplification of ica operon

The primers were synthesized by Genomed (Poland).

The presence of the entire ica operon was verified in SA and SE strains by the amplification of a $2.7 \mathrm{~kb}$ gene product encompassing a region of the icaADBC locus [13].

For the assay, 5'-TGCACTCAATGAGGGAATCA was used as the forward primer, and $5^{\prime}$-AATCACTACCGGAAACAGCG was used as the reverse primer [13].

The PCR reaction was conducted in a $50 \mu$ volume containing the above-mentioned primers $(1 \mu \mathrm{mol}$ each), together with the extracted bacterial DNA, $0.2 \mathrm{mM}$ of each of dATP, dCTP, dGTP, dDTP, $1.25 \mathrm{U}$ Dream Taq Polymerase, and 10X Dream Taq Buffer (Thermo Scientific).

A thermal profile of the reaction was as follows: incubation at $95{ }^{\circ} \mathrm{C}$ for $2 \mathrm{~min}$, followed by 35 cycles at $95{ }^{\circ} \mathrm{C}$ for $30 \mathrm{~s}$ (denaturation), $55^{\circ} \mathrm{C}$ for $30 \mathrm{~s}$ (annealing), $72{ }^{\circ} \mathrm{C}$ for $2 \mathrm{~min}$. (extension), and $72{ }^{\circ} \mathrm{C}$ for $10 \mathrm{~min}$. (final extension) after the 35 cycles.

After amplification, $10 \mu \mathrm{l}$ of the PCR mixture was analysed by agarose gel electrophoresis (2\% agarose in Tris-borate-EDTA). Molecular weight DNA Marker 3 (A\&A Biotechnology, Poland) was used.

Phenotypic characterization of the biofilmproducing ability

Quantitative determination of biofilm production was performed with the use a microtitre plate assay (MPA) 
with crystal violet. Briefly, the overnight bacterial culture of each tested bacterial isolate was adjusted with tryptic soy broth (TSB, BioMérieux) to match the turbidity of $0.5 \mathrm{McFarland}$ standard. The suspension was subsequently incubated overnight at $37{ }^{\circ} \mathrm{C}$. The solution was diluted 1:100 in TSB and $200 \mu \mathrm{l}$ aliquots were inoculated into three wells each of the 96-well sterile microtitre plate. The plates were incubated overnight at $37{ }^{\circ} \mathrm{C}$ in air, washed, and stained with $0.1 \%$ crystal violet. The optical density was measured at $570 \mathrm{~nm}$. The following values of absorbance were used for the interpretation of the biofilm forming capacity [14]:

- $\leq .120$ : the isolate classified as nonadherent (biofilm-negative)

- $>0.120 \leq 0.240$ : the isolate classified as weakly adherent

- $>0.240$ : the isolate classified as strongly adherent

A reference strain of S. epidermidis ATCC 35984 was used as a positive control.

Cell line culture and preparation of bacteria for in vitro experiments

Detroit 562 (CCL-138, ATCC), a human epithelial cell line derived from pharyngeal carcinoma, was maintained in a continuous culture in DMEM medium (Corning) containing 10\% heat-inactivated foetal bovine serum (FBS; SIGMA Aldrich) at $5 \% \mathrm{CO}_{2}$ at $37{ }^{\circ} \mathrm{C}$.

For in vitro experiments, $\mathrm{SE}(n=26)$ and SA $(n=26)$ strains were used. Bacterial strains were incubated to mid log phase $(\mathrm{OD} 600=0.6)$ in $5 \mathrm{ml}$ of tryptic soy broth (TSB; Oxoid) at $37{ }^{\circ} \mathrm{C}$ under constant rotation. The cells were then harvested by centrifugation $(2.500 \times \mathrm{g}$ for $5 \mathrm{~min})$ and washed twice in PBS. Bacterial chains and aggregates were broken by mild sonication for $3 \times 10 \mathrm{~s}$. at $30 \mathrm{~W}$ (Bransonic ultrasonic cleaner; G. Heinemann) on ice. Samples were then centrifuged $(5.000 \times \mathrm{g}$ for $10 \mathrm{~min}$ ), and the pellets were resuspended in DMEM. The accuracy of preparation of bacterial samples was routinely verified by plating dilutions on agar plates and counting colonies to determine colony forming units (CFU) per ml.
Internalization assay

For internalization assay, Detroit 562 cells $\left(3 \times 10^{5}\right.$ cells/well) were plated in a 24-well culture plate and infected by bacteria at MOI of 30 . Detroit cells and staphylococci were cocultured for $2 \mathrm{~h}$ in humidified atmosphere containing $5 \% \mathrm{CO}_{2}$. Internalization was stopped by placing the plate on ice and washing the cells twice with ice-cold PBS to remove non-internalized bacteria. The culture medium was replaced by DMEM with 10\% FBS containing gentamicin $(100 \mu \mathrm{g} / \mathrm{ml})+$ vancomycin overnight. After the incubation, the cells were washed with PBS and the medium was changed again to fresh media without antibiotics, and the culture was intended for determination of bacterial cytotoxicity assay.

Determination of cytotoxicity using the lactate dehydrogenase $[\mathrm{LDH}]$ release assay

To determine the cytotoxic properties of the tested bacterial strains in cultured Detroit 562 cells, the commercially available Pierce LDH Cytotoxicity Assay Kit (Thermo Scientific) was used, following the manufacturer's instructions. The specific cytotoxicity was calculated using the following formula:

$\%$ cytotoxicity $=($ tested $\mathrm{LDH}$ activity - control LDH activity)/(maximum LDH activity-spontaneous LDH activity) $\times 100$.

Relative amounts of LDH release were measured (absorbance at $490 \mathrm{~nm}$ ) using an ELISA plate reader. The cytotoxic activity of tested staphylococcal strains was determined $24 \mathrm{~h}$ after internalization and expressed as the percentage of killed cells. All assays were performed in three independent replications.

Staphylococcal attachment to Detroit 562 cell line as assessed by flow cytometry (adhesion assay)

Detroit 562 cells were seeded at $2 \times 10^{5}$ cells per well onto 24-well tissue culture plates in $1 \mathrm{~mL}$ of DMEM medium and cultured at $37{ }^{\circ} \mathrm{C}$ in $5 \% \mathrm{CO}_{2}$ for $1-2$ days until $80-90 \%$ confluency. The viability of the Detroit was confirmed by staining with $0.2 \% \mathrm{w} / \mathrm{v}$ trypan blue (Sigma Aldrich).

Bacteria labelled with BODIPY-FL (Molecular Probes) at MOI 40 were inoculated with the cells for $15 \mathrm{~min}$ at $37{ }^{\circ} \mathrm{C}$ in $5 \% \mathrm{CO} 2$. To stop the internalization, plates were placed on ice for $5 \mathrm{~min}$. Non- 
adherent staphylococci were removed by washing the cells three times with ice-cold PBS. After detaching the Detroit cells, they were transferred to clean tubes and centrifuged $\left(200 \times \mathrm{g}, 5 \mathrm{~min} ., 4{ }^{\circ} \mathrm{C}\right)$. The cell pellets were resuspended in one $\mathrm{mL}$ of cold DMEM culture medium and then processed through the flow cytometry. Bacteria attached to Detroit were quantified by a flow cytometer BD FACSCCalibur (BD Bioscience) using BD CellQuest software (BD Bioscience). A minimum of 50,000 cells was measured in each sample. This experiment was repeated three times for each strain.

\section{Statistical analysis}

Data are expressed as means \pm SD of a minimum of two independent experiments. Data were assessed with non-parametric Mann-Whitney test (for independent variables) to compare the differences between the two types of staphylococcus. Non-parametric chisquare test (for qualitative variables) was used to compare the frequency of the analysed categories depending on the type of staphylococcus. Spearman correlation coefficient test was used to determine the relationship between the examined features. $\mathrm{P}$ values of $<0.05$ were considered to be statistically significant.

\section{Results}

The ica genes detection by PCR and its correlation to the phenotypic biofilm production

Overall, the ica genes were detected by PCR in seven (26.9\%) out of $26 \mathrm{SE}$ isolates and in 11 (42.3\%) out of $26 \mathrm{SA}$ isolates included in the study.

Nevertheless, we detected high diversity of the detected ica profiles (Figs. 1, 2). Only, a minority of the isolates (represented only by SE) were positive for both the icaAD and the ica operon which was indicative of a complete set of genes required of the PIA synthesis.

Overall, the ica profiles detected by PCR included the $i c a D(10 / 38.4 \% \mathrm{SA}$ isolates), icaAD + ica operon (4/15.3\% SE isolates), icaAD (1/3.8\% SA isolate and $2 / 7.6 \% \mathrm{SE}$ isolates), and icaA (1/3.8\% SE isolate). The results of the PCR ica detection in all isolates included in the study are demonstrated in Table. 1.
In spite of the low level of the ica detection in the analysed staphylococci, all tested isolates demonstrated adherence capabilities under applied in vitro conditions. Strong biofilm production identified on the basis of criteria adopted from Christensen et al. was detected in the cumulative number of 12 (23\%) out of the 52 staphylococcal isolates (Christensen et al., [14]). The remaining isolates were classified as weak biofilm producers. The results of the phenotypic biofilm production using the MTP assay are demonstrated in Table 1.

Comparable numbers of SA $(26.9 \%)$ and SE $(19.2 \%)$ isolates were strong biofilm producers. Among five SE strong biofilm producers only three were both the icaAD- and ica operon-positive. The remaining proficient biofilm producers among SE isolates were ica-negative. Among seven SA strong biofilm producers only one was positive for the icaD gene. The remaining proficient biofilm producers among SA isolates were ica-negative.

The greatest biofilm biomass (OD $>0.5)$ was observed for three SE isolates positive for both the ica operon and icaAD. Nevertheless, in the group of ica AD- and ica operon-positive SE isolates, one isolate (no. 31) most probably did not produce a functional PIA under experimental conditions since it was classified as a weakly adherent isolate $(\mathrm{OD}=0.161)$.

Antibiotic resistance in correlation to the ica gene profiles and phenotypic biofilm production

Methicillin resistance (MR) was detected in $9(34.6 \%)$ SE and 7 (26.9\%) SA isolates (not significant). Twelve out of the $16(75 \%)$ MR isolates were multidrug resistant/MDR (resistant to $\geq 3$ antimicrobial groups).

MR was most frequently accompanied by resistance to macrolides, lincosamides and group B streptogramins ( MLS $_{\mathrm{B}}$ phenotype)-detected in 12 out of the $16 \mathrm{MR}$ (75\%) isolates and fluoroquinolones-detected in $8(50 \%)$ MR isolates. As many as six of the fluoroquinolone-resistant isolates were resistant to all tested agents belonging to this group of antimicrobials including NOR, CIP, OFX, MXF, and LVX. Aminoglycoside resistance was observed in $7(43.7 \%)$ MR isolates with diverse resistance profiles: $\mathrm{GM}+\mathrm{N}+\mathrm{AN}-2$ isolates, GM-1 isolate, $\mathrm{GM}+\mathrm{N}-1$ isolate, $\mathrm{AN}+\mathrm{N}-3$ isolates. 


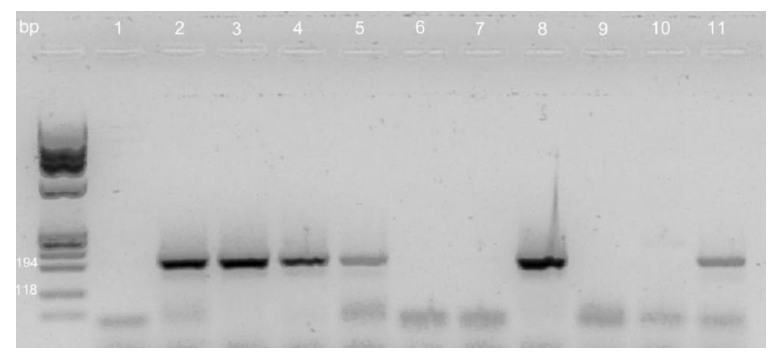

Fig. 1 PCR detection of the icaA and icaD genes in SA and SE isolates. Lane 1, absence of amplification product from a strong SE biofilm producer (31 III SE); Lane 2, icaA-positive, strong SE biofilm producer (21 SE); Lane 3, icaD-positive, strong SE biofilm producer (21 SE); Lane 4, icaA-positive, weak SA biofilm producer (40 SE); Lane 5, icaD-positive, weak SA biofilm producer (40 SE); Lanes 6-7, icaA- and icaD-negative (respectively) strong SA biofilm producer (54 SA); Lane 8, icaD-positive, weak SA biofilm producer (25 SA); Lanes 9-10, icaA- and icaD-negative (respectively) weak SE biofilm producer (42 SE); Lane 11, icaA-positive, weak SE biofilm producer $(13 \mathrm{SE})$;

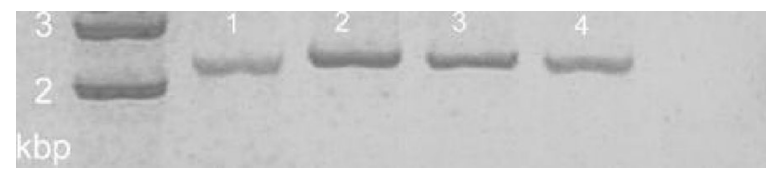

Fig. 2 PCR detection of the ica locus in SE isolates. Lanes 1-3, ica locus-positive, strong SE biofilm producers (21 SE, 31 III SE, 35 $\mathrm{SE}$ ); Lane 4, ica locus-positive, weak SE biofilm producer (31 SE)

Chloramphenicol, co-trimoxazole, and tetracycline resistance was detected in $4(25 \%), 3(18.7 \%)$, and 3 (18.7) MR isolates, respectively.

Methicillin susceptible isolates exhibited $\mathrm{MLS}_{\mathrm{B}}$ resistance phenotype most frequently (10 out of 36 isolates $/ 27.7 \%)$, followed by tetracycline resistance ( 6 isolates/16.6\%).

We did not observe any correlation between methicillin resistance (MR) and the ica genes presence and/or the phenotypic biofilm production.

Strong biofilm production was observed for only three MR staphylococcal isolates (one SE and two SA) and only one of these isolates (SE no. 21) harboured the icaAD and ica operon correlating to the production of the functional PIA.

Moreover, among the $12 \mathrm{MR}$ isolates defined as multidrug resistant, two MRSA isolates (no. 54, 56) were strongly adherent but ica-negative and one MRSE isolate (no. 21) was a strong biofilm producer positive for the icaAD and ica operon.

It should also be mentioned that strong biofilm production was detected in two other MDR, but methicillin-sensitive isolates represented by SE (no. 34 and 35). One of these isolates (no. 34) was icaAD and ica operon-positive.

Among the remaining 20 staphylococcal isolates fully susceptible to the tested antimicrobial agents (5
SE isolates and $15 \mathrm{SA}$ isolates), four SA isolates were icaD-positive (and weakly adherent by the MTP assay) and $1 \mathrm{SA}$ isolate was icaAD-positive (and weakly adherent by the MTP assay).

Attachment of S. epidermidis and S. aureus to cultured epithelial cells

Cells originating from nasopharynx were used as host cells to assess the capacity of SE $(n=26)$ and SA $(n=26)$ strains to attach. All tested bacterial strains, both $S$. aureus and S. epidermidis attached to Detroit 562 cell line after $15 \mathrm{~min}$. contact. The ability of the tested strains to attach to the Detroit cells was variable, ranging from $15.8 \%$ (strain no. 1) to $44 \%$ (strain no. 30) for SA and $15.1 \%$ (strain no. $31 \mathrm{VII}$ ) to $69.8 \%$ (strain no. 17) for SE. S. aureus isolates however showed the statistically highest attachment capacity, while SE strains showed a lower attachment pattern ( $p<0.05$; Fig. 3). As presented on Fig. $4 \mathrm{a}$, in 17 cases $(65 \%)$ of SE strains, less than $20 \%$ of their cells attach to epithelial cells. Similarly, low attachment ability was observed only in 6 out of 26 (23\%) SA strains (Fig. 4b).

In order to check whether bacterial ability to attach to epithelial cells corresponds with their ability to form biofilm, statistical analysis of correlation between 
Table 1 Characterization of staphylococcal isolates associated with conjunctivitis: ica gene detection profiles, phenotypic biofilm production, and antibiotic resistance results

\begin{tabular}{|c|c|c|c|c|}
\hline No & $\begin{array}{l}\text { Isolate } \\
\text { no }\end{array}$ & Antibiotic resistance profile & $\begin{array}{l}\text { Mean absorbance value (OD570)/ biofilm } \\
\text { production capability** }\end{array}$ & $\begin{array}{l}\text { ica genes detected } \\
\text { by PCR }\end{array}$ \\
\hline \multicolumn{5}{|c|}{ Staphylococcus epidermidis isolates } \\
\hline 1 & $2 \mathrm{SE}$ & Fully susceptible & $0.135 /$ weak & - \\
\hline 2 & $7 \mathrm{SE}$ & $\mathrm{TE}$ & $0.143 /$ weak & - \\
\hline 3 & $12 \mathrm{SE}$ & Fully susceptible & $0.149 /$ weak & - \\
\hline 4 & $13 \mathrm{SE}$ & SXT, OFX & $0.150 /$ weak & icaA \\
\hline 5 & $17 \mathrm{SE}$ & $\mathrm{MLS}_{\mathrm{B}}$ & $0.142 /$ weak & - \\
\hline 6 & $18 \mathrm{SE}$ & Fully susceptible & $0.144 /$ weak & \\
\hline 7 & $19 \mathrm{SE}$ & Fully susceptible & $0.148 /$ weak & \\
\hline 8 & $20 \mathrm{SE}$ & $\mathrm{MLS}_{\mathrm{B}}$ & $0.173 /$ weak & - \\
\hline 9 & $21 \mathrm{SE}^{*}$ & FOX, TE, C & $0.599 /$ strong & icaAD, \\
\hline \multicolumn{5}{|c|}{ ica operon } \\
\hline 10 & $23 \mathrm{SE}^{*}$ & $\begin{array}{l}\text { FOX, MLS } \\
\quad \text { SXT }\end{array}$ & $0.187 /$ weak & icaAD \\
\hline 11 & $28 \mathrm{SE}^{*}$ & $\begin{array}{l}\text { FOX, } \text { MLS }_{\mathrm{B}}, \mathrm{NOR}, \mathrm{CIP}, \mathrm{OFX}, \mathrm{LVX}, \mathrm{MFX} \\
\text { GM, AN, N }\end{array}$ & $0.175 /$ weak & icaAD \\
\hline 12 & $31 \mathrm{SE}^{*}$ & $\begin{array}{l}\text { FOX, MLS } \\
\text { GM, NOR, CIP, OFX, LVX, MFX, }\end{array}$ & $0.161 /$ weak & icaAD, \\
\hline \multicolumn{5}{|c|}{ ica operon } \\
\hline 13 & 31 I SE & $\mathrm{FOX}, \mathrm{MLS}_{\mathrm{B}}$ & $0.142 /$ weak & - \\
\hline 14 & $\begin{array}{l}31 \mathrm{III} \\
\text { SE }\end{array}$ & $\mathrm{MLS}_{\mathrm{B}}$ & $0.645 /$ strong & icaAD, \\
\hline \multicolumn{5}{|c|}{ ica operon } \\
\hline 15 & $\begin{array}{l}31 \mathrm{VII} \\
\text { SE }\end{array}$ & $\mathrm{MLS}_{\mathrm{B}}$ & $0.252 /$ strong & - \\
\hline 16 & $\begin{array}{l}\text { 31VIII } \\
\text { SE }\end{array}$ & FOX & $0.166 /$ weak & - \\
\hline 17 & A SE & $\mathrm{MLS}_{\mathrm{B}}$ & $0.149 /$ weak & - \\
\hline 18 & $33 \mathrm{SE}$ & Fully susceptible & $0.135 /$ weak & - \\
\hline 19 & $34 \mathrm{SE}^{*}$ & $\begin{array}{l}\text { MLS }_{B}, \text { TE, CIP, OFX, LFX, GM, AN, N, } \\
\text { SXT }\end{array}$ & $0.339 /$ strong & - \\
\hline 20 & $35 \mathrm{SE}^{*}$ & MLS $_{\mathrm{B}}, \mathrm{TE}, \mathrm{OFX}, \mathrm{SXT}$ & $0.552 /$ strong & icaAD, \\
\hline \multicolumn{5}{|c|}{ ica operon } \\
\hline 21 & $36 \mathrm{SE}^{*}$ & $\mathrm{FOX}, \mathrm{MLS}_{\mathrm{B}}, \mathrm{SXT}$ & $0.136 /$ weak & - \\
\hline 22 & $39 \mathrm{SE}$ & $\mathrm{TE}$ & $0.151 /$ weak & - \\
\hline 23 & $42 \mathrm{SE}^{*}$ & $\begin{array}{l}\text { FOX, MLS } \\
\text { MFX, TE, NOR, N, SXT }\end{array}$ & $0.184 /$ weak & - \\
\hline 24 & $45 \mathrm{SE}$ & $\mathrm{FOX}, \mathrm{N}$ & $0.193 /$ weak & - \\
\hline 25 & $46 \mathrm{SE}$ & $\mathrm{MLS}_{\mathrm{B}}$ & $0.129 /$ weak & - \\
\hline 26 & $49 \mathrm{SE}$ & $\mathrm{MLS}_{\mathrm{B}}$ & $0.128 /$ weak & - \\
\hline \multicolumn{5}{|c|}{ Staphylococcus aureus isolates } \\
\hline 1 & 1SA & Fully susceptible & $0.169 /$ weak & ica D \\
\hline 2 & $3 \mathrm{SA}$ & Fully susceptible & $0.179 /$ weak & ica D \\
\hline 3 & $4 \mathrm{SA}$ & $\mathrm{TE}$ & $0.162 /$ weak & - \\
\hline 4 & $5 \mathrm{SA}$ & Fully susceptible & $0.348 /$ strong & - \\
\hline 5 & $6 \mathrm{SA}$ & Fully susceptible & $0.157 /$ weak & - \\
\hline
\end{tabular}


Table 1 continued

\begin{tabular}{|c|c|c|c|c|}
\hline No & $\begin{array}{l}\text { Isolate } \\
\text { no }\end{array}$ & Antibiotic resistance profile & $\begin{array}{l}\text { Mean absorbance value (OD570)/ biofilm } \\
\text { production capability** }\end{array}$ & $\begin{array}{l}\text { ica genes detected } \\
\text { by PCR }\end{array}$ \\
\hline 6 & $8 \mathrm{SA}$ & TE, GM, N & $0.189 /$ weak & icaD \\
\hline 7 & $9 \mathrm{SA}$ & Fully susceptible & $0.162 /$ weak & - \\
\hline 8 & $10 \mathrm{SA}$ & Fully susceptible & $0.153 /$ weak & - \\
\hline 9 & $11 \mathrm{SA}$ & Fully susceptible & $0.337 /$ strong & ica D \\
\hline 10 & $15 \mathrm{SA}$ & Fully susceptible & $0.273 /$ strong & - \\
\hline 11 & $16 \mathrm{SA}$ & Fully susceptible & $0.206 /$ weak & - \\
\hline 12 & $22 \mathrm{SA}$ & Fully susceptible & $0.200 /$ weak & ica D \\
\hline 13 & $24 \mathrm{SA}$ & Fully susceptible & $0.205 /$ weak & ica D \\
\hline 14 & $25 \mathrm{SA}^{*}$ & FOX, MLS $_{B}$, NOR, CIP, C & $0.212 /$ weak & IcaD \\
\hline 15 & $30 \mathrm{SA}^{*}$ & $\mathrm{FOX}, \mathrm{MLS}_{\mathrm{B}}, \mathrm{C}$ & $0.185 /$ weak & IcaD \\
\hline 16 & $32 \mathrm{SA}$ & Fully susceptible & $0.264 /$ strong & - \\
\hline 17 & $37 \mathrm{SA}$ & Fully susceptible & $0.204 /$ weak & - \\
\hline 18 & $40 \mathrm{SA}$ & Fully susceptible & $0.158 /$ weak & ica $\mathrm{AD}$ \\
\hline 19 & $47 \mathrm{SA}$ & $\mathrm{TE}$ & $0.468 /$ strong & - \\
\hline 20 & $48 \mathrm{SA}$ & $\mathrm{MLS}_{\mathrm{B}}$ & $0.138 /$ weak & - \\
\hline 21 & $50 \mathrm{SA}^{*}$ & $\mathrm{FOX}, \mathrm{MLS}_{\mathrm{B}}, \mathrm{GM}, \mathrm{AN}, \mathrm{N}$ & 0.191/weak & $\mathrm{icaD}$ \\
\hline 22 & $53 \mathrm{SA}$ & $\mathrm{FOX}, \mathrm{MLS}_{\mathrm{B}}$ & $0.186 /$ weak & $\mathrm{icaD}$ \\
\hline 23 & $54 \mathrm{SA}^{*}$ & $\begin{array}{l}\text { FOX, MLS } \\
\text { AN, NOR, CIP, OFX, LVX, MFX, }\end{array}$ & $0.383 /$ strong & - \\
\hline 24 & $56 \mathrm{SA}^{*}$ & $\begin{array}{l}\text { FOX, MLS } \\
\text { AN, NOR, CIP, OFX, LVX, MFX, }\end{array}$ & $0.328 /$ strong & - \\
\hline 25 & $57 \mathrm{SA}^{*}$ & $\begin{array}{l}\text { FOX, MLS } \\
\text { AN, NOR, CIP, OFX, LVX, MFX, }\end{array}$ & $0.203 /$ weak & - \\
\hline 26 & $58 \mathrm{SA}$ & Fully susceptible & $0.153 /$ weak & - \\
\hline
\end{tabular}

*Multidrug resistance (MDR); **OD $\leq 0.120$ - non-adherent; OD $>240$ - strongly adherent; OD > $120 \leq 0.240-$ weakly adherent; SA - Staphylococcus aureus, SE—Staphylococcus epidermidis, MLS $_{\mathrm{B}}$ — cross-resistance to macrolides, lincosamides, and streptogramin B, cefoxitin; detection of methicillin resistance (FOX), erythromycin (E), clindamycin (CC), tetracycline (TE), norfloxacin (NOR), ciprofloxacin (CIP), ofloxacin (OFX), levofloxacin (LVX), moxifloxacin (MXF), gentamicin (GM), amikacin $(\mathrm{AN})$, neomycin $(\mathrm{N})$, chloramphenicol $(\mathrm{C})$, co-trimoxazole (TMP/SXT)

these two traits of tested staphylococcal strains was performed. As a result, no correlation between attachment to host cells and biofilm formation was found. This finding indicates that different bacterial factors are involved in both determinants of pathogenicity of staphylococci.
Lactate dehydrogenase (LDH) measurementcytotoxic abilities of different staphylococcal clinical isolates

To investigate whether clinical isolates of SE and SA have the ability to kill host epithelial cells, their cytotoxic potential was evaluated in relation to Detroit cell line. The integrity of plasma membrane of host cells infected with MOI 30 of SA and SE clinical isolates was shown by measuring $\mathrm{LDH}$ released into the culture media $24 \mathrm{~h}$ post infection. The cytotoxic ability of SA strains to kill host epithelial cells was 
Fig. 3 Assessment of the attachment value in $S$. aureus and $S$. epidermidis strains (pooled data)

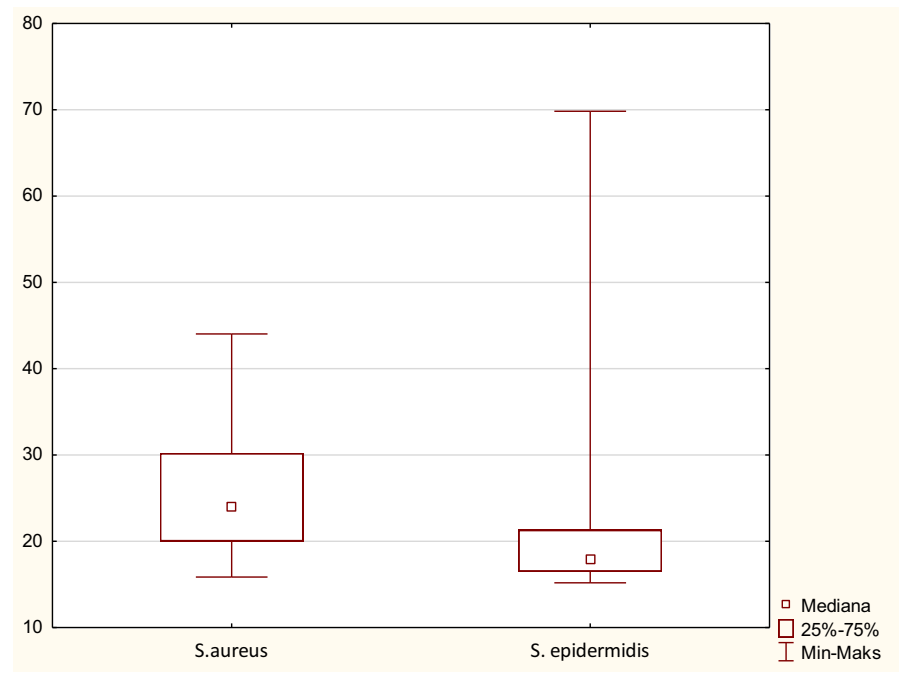

significantly higher than that observed in SE ( $p<0.05$; Fig. 5). As presented on Fig. 6b, most of the $S$. aureus strains (17 of 26 [65\%]) proved to be able to kill epithelial cells after overnight incubation. But only a fraction of these isolates $(11 ; 46 \%)$ produced significant $(>20 \%$ of host cells killed; $p<0.05$ ) cytotoxicity $24 \mathrm{~h}$ after infection at MOI of 30 . In contrast, SE strains showed weak cytotoxicity in relation to the host cells. Only in 3 cases (11.5\%) cytotoxicity exceeded low $10 \%$ (Fig. 6a). Among highly toxic SA strains (11 strains no. 1, 16, 25, 30, 32, $37,40,50,54,56,57) 6(54.5 \%)$ were MDR (no. 25 , $30,50,54,56,57)$, and they represented all MDR strains in a group of SA. Such a relationship was not noticed in the case of SE strains. Here, only one strain, no. 34, exhibited both weak cytotoxicity and MDR features.

\section{Discussion}

For a majority of microorganisms, establishing an infection is a multifunctional process and different virulence factors can be involved in its pathogenesis. However, there is a correlation between bacterial strains isolated from specific diseases and the expression of specific virulence factors, which may indicate their special role in its pathogenesis [15]. An important feature of staphylococci, which has a great influence on the development of conjunctivitis, is the ability to adhere to artificial surfaces as well as to living cells and production of biofilm structures. It is crucial first step for the initiation of infection for the bacteria remaining in the colonized area. The area of the eyeball and conjunctiva is a place where there are a number of components that create a favourable environment for the development of bacteria, especially those producing large amounts of exogenous protein substances. Adherence and the formation of biofilm structures are important elements that affect the chronic, lasting even several weeks, character of conjunctivitis [15-17].

The results of our study are indicative of common adherence abilities demonstrated by staphylococcal strains involved in the aetiology of conjunctivitis as all tested isolates were capable of the biofilm development. Nevertheless, strong biofilm production mediated by the presence of a complete ica operon and subsequent production of a biologically active PIA evidenced by high absorbance values in the MTP assay was observed for only a minority of them.

The ica genes were detected by PCR in seven (26.9\%) SE and in 12 (46.1\%) SA isolates included in the study. Low prevalence of ica genes is staphyloccal isolates associated with ocular infections has also been reported in previous studies. Sharifinejad et al. observed that keratitis and endophthalmitis SE isolates showed the icaA +, icaD +, is $256+$ gene profile more frequently $(55.5 \%$ and $50 \%$, respectively) than isolates cultured from the conjunctiva, nasolacrimal duct, and the eyelid for which the predominant $(61 \%)$ profile was icaA-, icaD-, is256- [4]. Similarly, FloresPáez et al. reported a low frequency predominance of $20-40 \%$ of $i c a A$, icaD genes and IS256 distributed 
a

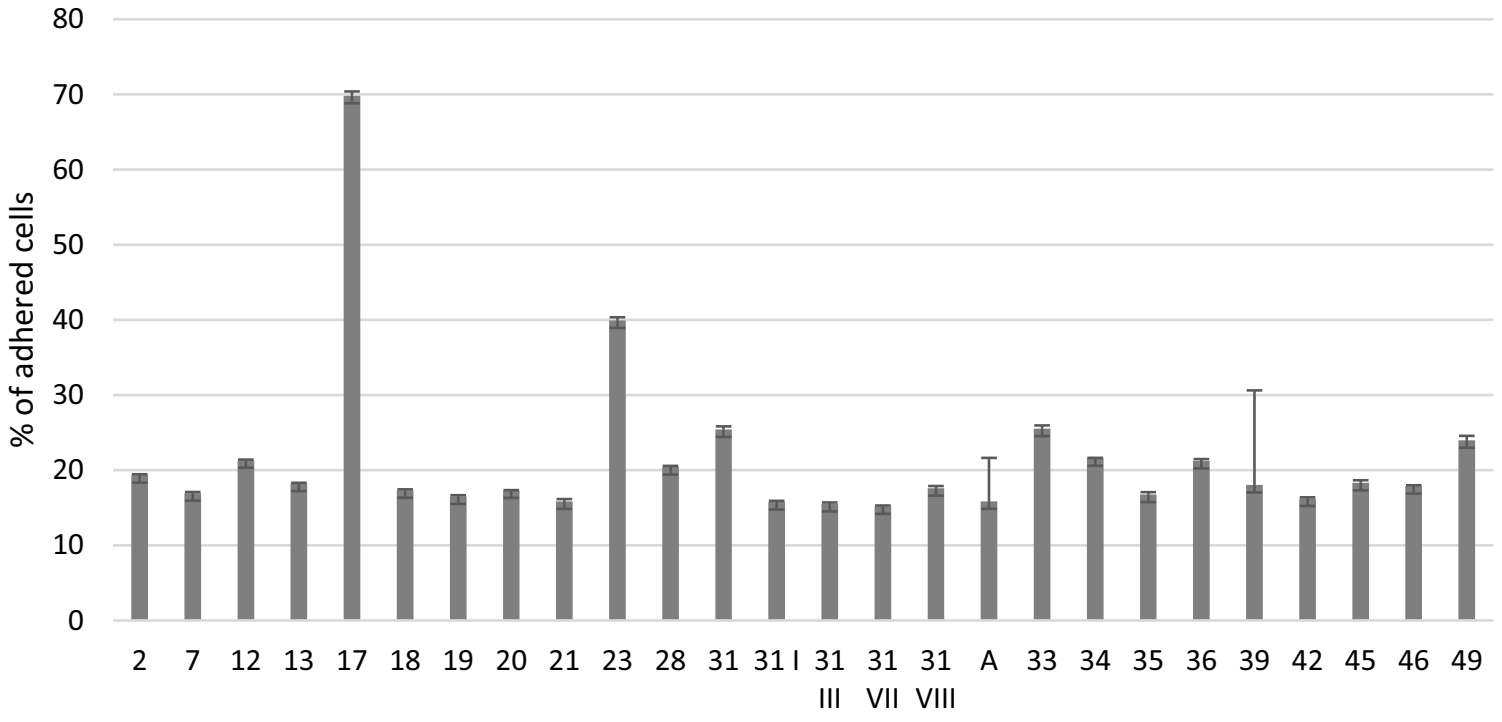

S.epidermidis strains

b

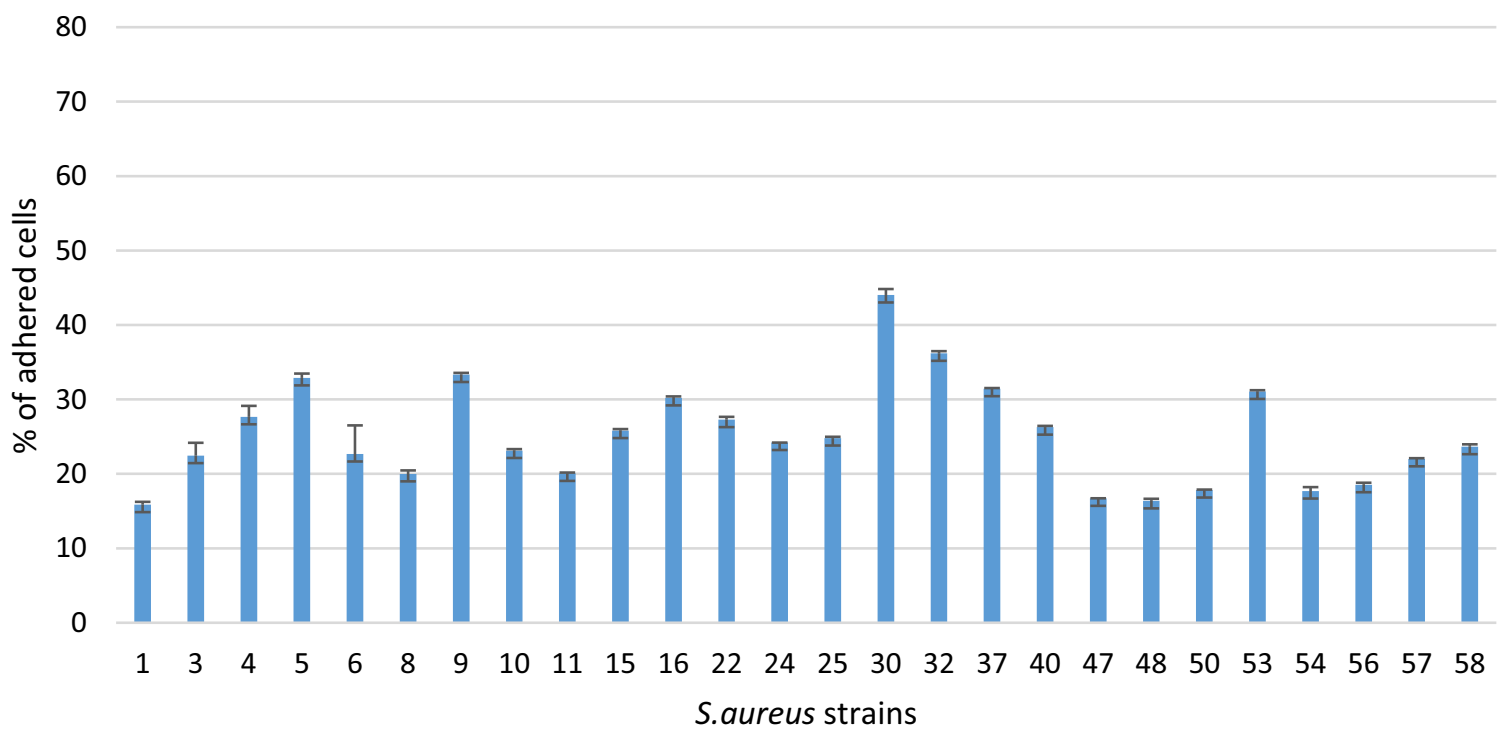

Fig. 4 Attachment to Detroit 562 cells by different staphylococcal clinical isolates. a represents attachment ability of $S$. epidermidis strains. b represents attachment ability of $S$. aureus strains Results expressed as mean \% of attached bacterial cells/ 50000 epithelial cells \pm SD from at least three independent experiments 
Fig. 5 Cytotoxic properties of Staphylococcus aureus strains and S. epidermidis strains (pooled data)

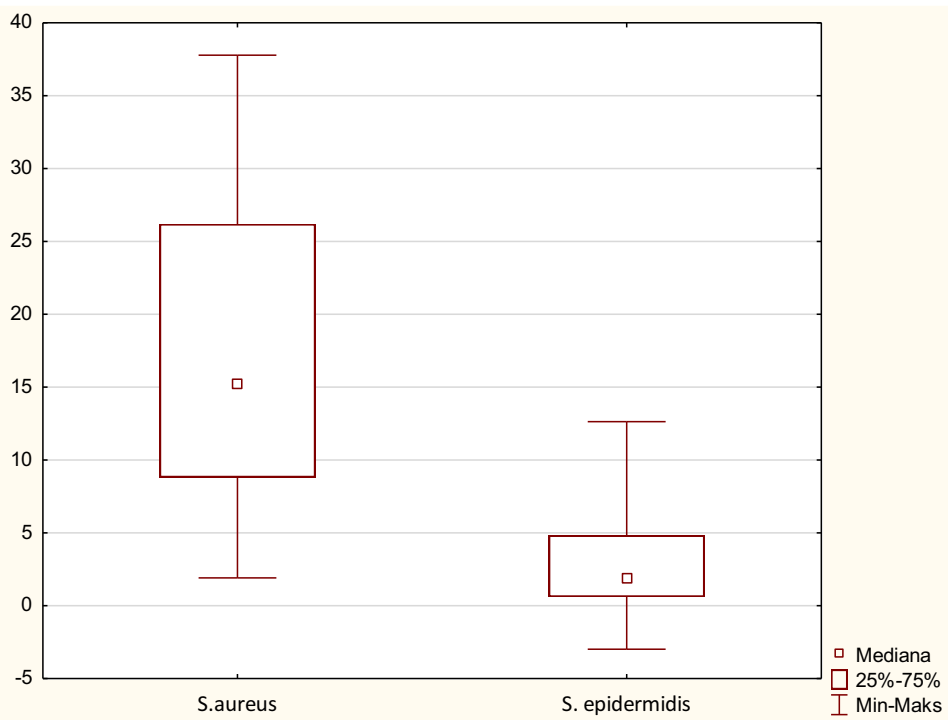

homogenously between identified sequence types of SE isolates cultured from the ocular infections including conjunctivitis and from the healthy conjunctiva samples (no statistical significance) [2].

In addition to relatively low level of ica genes detection, a high diversity of the PCR detected ica profiles was observed in the study reported here. It should also be highlighted that only four (7.6\%) out of the 52 analysed isolates, represented only by SE, were both the icaAD- and ica operon-positive. The remaining $i c a$-positive isolates were either icaA or icaD, or icaAD-positive and, interestingly, almost all of them (with the exception of one SA icaD-positive isolate) produced weak biofilm in the applied MTP assay. The results indicate that a complete set of four icaADBC genes arranged in a functional operon is the mainstay of the PIA-mediated biofilm formation.

Our results support the previous literature data on the necessity of the presence of a complete ica locus and the co-expression of icaA, icaD, and icaC for the functional PIA production [18]. Namely, three out of the four isolates reported as both icaAD and ica operon-positive were strong biofilm producers; another isolate with this gene profile was weakly adherent which, in turn, was indicative of low or even the lack of the expression of the PIA and suggested the alternative but much less efficient pathway of adherence. Piechota et al. who investigated the biofilm formation by SA strains isolated from hospitalized patients noted, in line with our results, that not all genes of the ica operon were detected in analysed strains and observed a statistically higher biofilm biomass in $i c a A D B C$ - (51.5\% of isolates) and icaADBpositive strains ( $26.1 \%$ of isolates) than in those which were only icaAD-positive (15.4\% of isolates) [19]. Elkhashab et al., in turn, who investigated 50 staphylococcal strains isolated from conjunctival swabs reported, in contrast to our results, that only $60 \%$ and $50 \%$ of SA and coagulase-negative staphylococci (CNS) isolates, respectively, were the biofilm producers phenotypically but all biofilm-forming isolates were positive for the icaA gene. Only, two out of their isolates produced the biofilm phenotypically but were negative for the icaA gene [3].

The discrepancy between the ica operon and icaAD detection observed in our study has several possible explanations. Bacterial strains can have only gene segments, not the whole and functional ica operon. Arciola et al. observed phase variants of slimeproducing SA and SE clinical isolates lacking the $i c a A$, icaD segments and even the entire ica locus [9]. Also, mutations or insertions (for example, IS256) inactivating the ica genes and influencing the PCR result may occur $[10,18]$.

In spite of the fact that the PIA production is still considered the main mechanism of the biofilm formation in both SA and SE, alternative, PIAindependent forms of the biofilm production have also been reported, especially for SA [10]. As Arciola et al. noted, the observation that a minor proportion of 
a

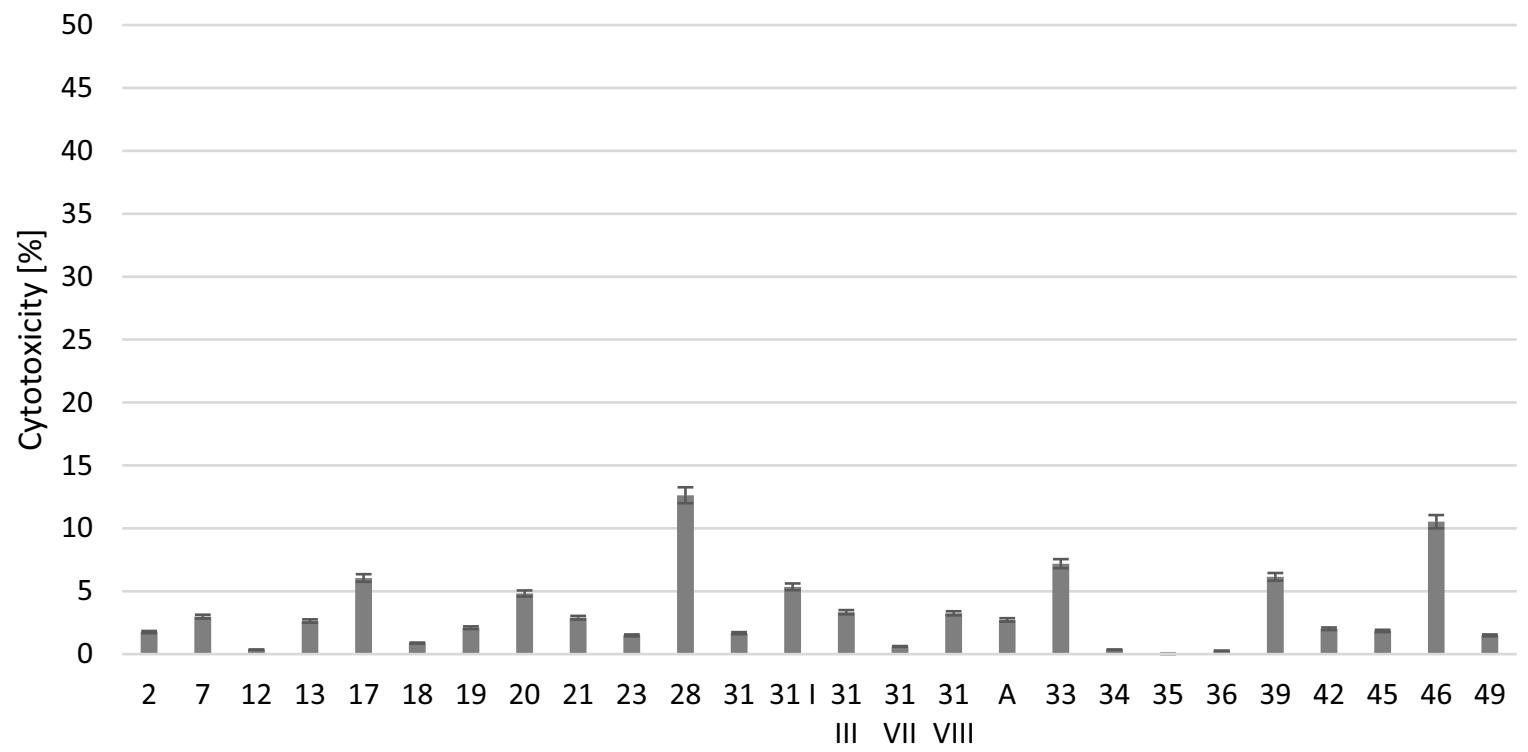

S. epidermidis strains

b

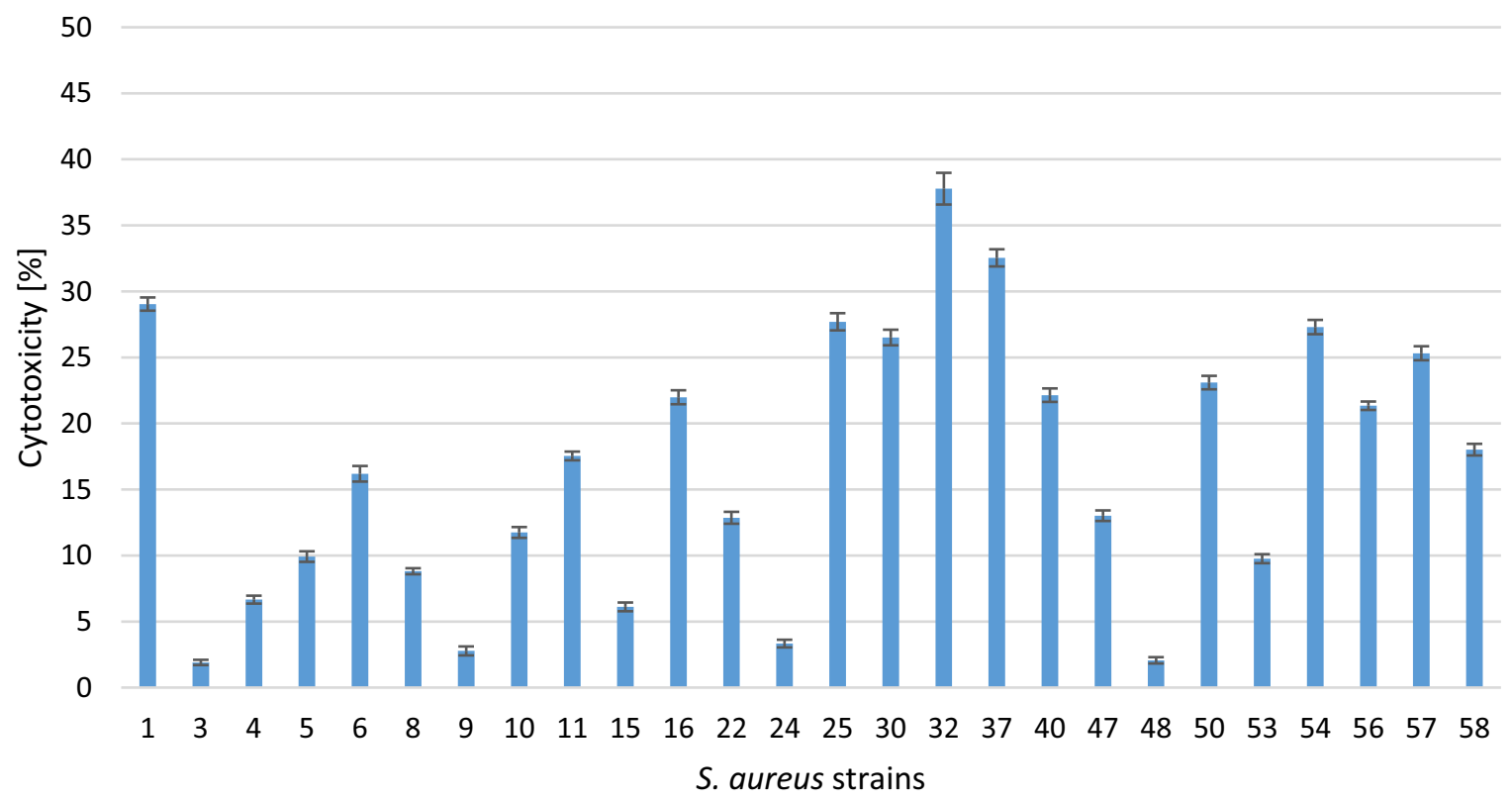

Results expressed as mean \% cytotoxicity on epithelial cells \pm SD from at least 3 independent experiments.

Fig. 6 Cytotoxicity of different $S$. aureus and $S$. epidermidis strains at MOI 30 on epithelial cell line. a represents cytotoxic ability of $S$. epidermidis strains. b represents cytotoxic ability of
S. aureus strains. Results expressed as mean \% cytotoxicity on epithelial cells \pm SD from at least 3 independent experiments 
SA strains can form biofilm even in the absence of the ica locus and that certain strains carrying such locus continue anyway to produce biofilm even after deletion of the locus is suggestive of existence of the icaindependent pathways [10].

Indeed, we observed that that seven (26.9\%) SA and five (19.2\%) SE isolates were identified as strong biofilm producers and for the majority of these isolates biofilm production was not dependent on the PIA, either due to the lack of the ica genes, or an incomplete ica profile. This observation was striking particularly for SA as none of the isolates was both ica operon and icaAD-positive. Also, as mentioned previously, only three SE isolates able to produce strong biofilm were positive for both the ica operon and icaAD. These isolates simultaneously developed the greatest biofilm biomass $(\mathrm{OD}>0.5)$ which suggested that the PIA expression largely contributed to their proficient biofilm production.

The biofilm matrix is composed of extracellular polymeric substances other than PIA including e-DNA, teichoic acids, and proteins. The candidate proteins involved in the biofilm production include Bap (biofilm-associated protein) considered to play a prevalent role in human infections caused by coagulase-negative staphylococci, Aap (accumulation-associated protein) in SE, as well as SasG, SasC, protein A, and fibronectin-binding proteins: FnBPA, FnBPB for SA [10]. Mechanisms involved in the ica-independent biofilms are multifactorial. According to Figuerido et al., they are performed with different strain backgrounds and the major biofilm structural components produced by a specific strain might not be the same for all bacterial strains. At the same time, the same strain may have multiple mechanisms for biofilm formation, depending on the environmental signals. This ability might represent a strategy for survival in the multifaceted host environmental context [20].

Alternative mechanisms of the biofilm production probably concur and can be switched on in different phases of the infectious process, adapting the characteristics of the biofilm extracellular matrix in response to external stimuli, in order to colonize and establish the infection in host tissue [10,20].

Since all staphylococcal isolates included in the study were capable of expression of their adherence abilities in the applied assay, it can be speculated that the PIA-independent mechanisms of the biofilm production do exist, and they are common among isolates associated with conjunctival infections. Also, in spite of the fact, that the PIA-independent biofilms tend to be weaker than those associated with the production of the polysaccharide [21], their production seems to be necessary and sufficient for the development of the infectious process in the conjunctiva.

Attachment of staphylococci to eukaryotic cells is a critical step to their pathogenesis. This initial attachment is dependent on bacterial cell wall-bound adhesins with the best documented role of MSCRAMMs. For many Gram-positive bacteria these surface proteins play a prominent role in the attachment and are strong primary factors required to facilitate the internalization process $([16,22]$. Specifically, for both SA and CoNS, the interaction between FnBP-fibronectin and integrin $\alpha 5 \beta 1$ on host cells is necessary and sufficient to promote bacterial adhesion and subsequent internalization [12, 16, 22].

The data of adhesion assay in which clinical isolates of SA and SE were in contact with host epithelial cells for 15 min revealed that SA isolates adhered more extensively to host cells than SE. This significant difference in the attachment ability between two tested Staphylococcal species seems to be caused by the type of host cells that were used for the experiment. As proved by Ridley et al., nasopharyngeal Detroit 562 cells have significantly lower fibronectin-binding capacity, which reflects $\alpha 5 \beta 1$ functionality on their surface. This fact resulted in relatively poor S. aureus adherence and invasion [22]. In our study, despite the limitations of Detroit cell line, SA adhered more extensively to the cells when compared to SE. This confirms that bacteria must use alternative mechanisms through which they become attached albeit at a lower level [17]. Among other attachment molecules, extracellular adherence protein (Eap), which is produced by all SA isolates but not by other staphylococcal species, was found to be important with respect to its adhesive functions, independent of the MSCRAMM-type adhesins $[6,16]$. Also, initial adhesion of SE to host cells and its internalization can be mediated by FnBP-Fn- $\alpha 5 \beta 1$ integrin pathway independent mechanisms or molecules.

It should also be noted that although the adherence capabilities and the subsequent biofilm production are crucial for the initiation and maintaining the infection, other aspects of bacterial pathogenesis including 
antibiotic resistance and cytotoxicity must be taken into account to unveil the pathogenesis of this type of infection.

Cell invasion of non-professional phagocytes, including epithelial cells, contributes to the infection development. Infections caused by SA are typically associated with death of the host cell and the process that is induced by the cumulative action of different bacterial components [6]. The cytotoxic activity is mainly elicited by the secreted cytotoxins, in particular staphylococcal $\alpha$-toxin. This major cytotoxic, pore-forming agent elaborated by SA, by inducing apoptosis causes cell membrane lysis and subsequently cell death. The toxin provokes apoptosis in a wide range of different mammalian cells and mediates ocular tissue damage [15]. The cytotoxic effect induced by bacteria is highly related to the virulence of the microorganism. Not surpassingly, in our study we observed that SA strains released higher level of LDH than SE strains, confirming the cytotoxic ability of $S$. aureus strains to kill host epithelial cells. Interestingly, $54.5 \%$ of SA strains that were highly cytotoxic were also multi-drug resistant. This observation is important for two reasons. First, infections caused by MRSA strains are difficult to treat and, in the case of ophthalmic infections, are rapidly progressing. Secondly, SA strains that are multi drug resistant, in particular MRSA, significantly influences the pathogenesis and pathology of conjunctival infections. Schlievert et al. analysed virulence of MRSA bacteria in terms of the toxin produced and found that the strains synthesized inflammatory cytolysins including $\alpha$-toxin, $\delta$-toxin, $\gamma$-toxin [23]. There is also an epidemiologic association of the SA MRSA (especially community acquired CA-MRSA) infections with production of PVL [15]. PVL is a cellspecific toxin able to lyse polymorphonuclear neutrophils. Even at low concentrations the toxin activates inflammatory response of neutrophils and thus contributes to pathogenesis of conjunctivitis [15]. Although the cell type that we used in our study is not a target for PVL, it must be taken into consideration that there may be more serious consequences from PVL-mediated lysis of host cells in response to SA MDR eye infection.

In our study SE showed less aggressiveness than SA. Indeed, SE as a commensal organism is adopted for the colonization of human skin rather than invasion. Even though it is involved in conjunctivitis, it should be regarded as an "accidental pathogen" responsible for chronic infections. Moreover, many of the factors important for commensal lifestyle of SE, such as the ability to form biofilm, are beneficial as virulence factors during infection [11, 12].

The mainstay of treatment for bacterial conjunctivitis is an empirical broad-spectrum antibiotic therapy. A significant obstacle, however, is the increasing resistance to first-line drugs among ocular, bacterial pathogens. Therefore, an important information characterizing the studied staphylococcal strains is the assessment of their drug resistance, especially in relation to the groups of drugs that are of the greatest importance in the treatment of conjunctivitis. The reported results indicate that antibiotic resistance is an important factor associated with the pathogenic potential of staphylococci associated with conjunctivitis, but we have not observed a correlation between antibiotic resistance and the ica gene profile or the phenotypic ability to produce biofilm. Methicillin resistance was detected in $34.6 \% \mathrm{SE}$ and $26.9 \%$ SA isolates with $75 \%$ of the MR isolates found. However, a strong biofilm production was observed for only one MRSE and two MRSA isolates among which only MRSE harboured both the icaAD and ica operon correlating to the production of the functional PIA. The remaining MR staphylococci were identified as weak biofilm producers positive either for the icaAD (2 SE isolates) or icaD (4 SA isolates) only, or icanegative (5 SE and $1 \mathrm{SA}$ isolate). The lack of a significant correlation between susceptibility to methicillin and biofilm formation was also reported by Smith et al. who tested 972 clinical SA isolates [24]. Sharifinejad et al., in turn, investigating SE associated with ocular infections reported that $82.6 \%$ of isolates with the mecA gene corresponding to methicillin resistance simultaneously possessed the adhesion operon genes which stands in contrast to results obtained in our study [4]. Elkhashab et al. also found a significant association between the presence of the icaA gene in staphylococcal strains isolated from conjunctival swabs and multidrug resistance as $89.5 \%$ and $72.7 \%$ of the MDR SA and SE, respectively, were icaA-positive [3]. Similarly, Fariña et al. found widely distributed capacity of the biofilm production in clinical SE ocular isolates especially those which were $m e c A$-positive and multidrug resistant. Biofilm and $m e c A$ were also detected more frequently in clinical SE than in those isolated from the healthy 
human conjunctiva $(75 \%$ and $70 \%$ vs. $36.3 \%$ and $18.2 \%$, respectively) [25]. Figueiredo et al., suggested, in turn, that the PIA type is more common in MSSA while ica-independent biofilms were more frequently observed in MRSA which can support the results obtained in our study as none of the MRSA isolates possessed a complete set of the ica genes [20].

\section{Conclusions}

The results are indicative of complexity of factors involved in the biofilm production in staphylococci associated with conjunctivitis. Adherence abilities were commonly observed in staphylococci associated with conjunctivitis. However, low prevalence of isolates positive for a complete and functional ica locus and low prevalence of strong biofilm producers was detected. Existence of ica-independent mechanisms of biofilm production seem to be more common in SA. At the same time, SA has a larger arsenal of effective factors and mechanisms responsible for adherence to eukaryotic cells than SE. It is more virulent compared to SE, which was manifested by a significantly higher percentage of strains causing damage to the host cell structures.

Author's contribution All authors contributed to the study conception and design. Material preparation, data collection, and analysis were performed by Ewa Jasińska, Agnieszka Bogut, and Agnieszka Magryś. The first draft of the manuscript was written by Agnieszka Bogut and Agnieszka Magryś. Alina Olender critically revised the work. All authors read and approved the final manuscript.

Funding The authors did not receive support from any organization for the submitted work.

\section{Declarations}

Conflict of interest All authors certify that they have no affiliations with or involvement in any organization or entity with any financial interest (such as honoraria; educational grants; participation in speakers' bureaus; membership, employment, consultancies, stock ownership, or other equity interest; and expert testimony or patent-licensing arrangements), or non-financial interest (such as personal or professional relationships, affiliations, knowledge or beliefs) in the subject matter or materials discussed in this manuscript.

Ethical approval All procedures performed in studies involving human participants were in accordance with the ethical standards of the institutional and/or national research committee and with the 1964 Helsinki declaration and its later amendments or comparable ethical standards.

Consent to participate For this type of study formal consent is not required.

Open Access This article is licensed under a Creative Commons Attribution 4.0 International License, which permits use, sharing, adaptation, distribution and reproduction in any medium or format, as long as you give appropriate credit to the original author(s) and the source, provide a link to the Creative Commons licence, and indicate if changes were made. The images or other third party material in this article are included in the article's Creative Commons licence, unless indicated otherwise in a credit line to the material. If material is not included in the article's Creative Commons licence and your intended use is not permitted by statutory regulation or exceeds the permitted use, you will need to obtain permission directly from the copyright holder. To view a copy of this licence, visit http://creativecommons.org/licenses/by/4.0/.

\section{References}

1. DeCory HH, Sanfilippo CM, Proskin HM, Blondeau JM (2020) Characterization of baseline polybacterial versus monobacterial infections in three randomized controlled bacterial conjunctivitis trials and microbial outcomes with besifloxacin ophthalmic suspension $0.6 \%$. PLOS ONE 15(8): 0237603

2. Florez-Páez LA, Zenteno JC, Alcántar MD, Vargas-Mendoza CF, Rodríguez-Martínez ME, Jan-Roblero J, CancinoDiaz JC (2015) Molecular and phenotypic characterization of Staphylococcus epidermidis isolates from healthy conjunctiva and a comparative analysis with isolates from ocular infection. PLoS ONE 10(8):e0135964. https://doi. org/10.1371/journal.pone.0135964

3. Elkhashab THT, Adel LA, Nour MS, Mahran M, Elkaffas M (2018) Association of intercellular adhesion gene A with biofilm formation in staphylococci isolates from patients with conjunctivitis. J. Lab. Phys. 10(3):309-315

4. Sharifinejad M, Shokatpour N, Farnaghi F, Abedinyfar Z, Amoli FA, Doustdar F (2018) Different genotypes of adhesion operon genes in Staphylococcus epidermidis isolates from various ocular infections. Eye Contact Lens 44(Suppl 2):S277-S280

5. Krut O, Utermohlen O, Schlossherr X, Kronke M (2003) Strain-specific association of cytotoxic activity and virulence of clinical Staphylococcus aureus isolates. Infect Imunn 71(5):2716-2723

6. Strobel M, Pfortner H, Tuchscherr L, Volker U, Schmidt F, Kramko N et al (2016) Post-invasion events after infection with Staphylococcus aureus are strongly dependent on both the host cell type and the infecting $S$. aureus strain. Clin Microbiol Infect 22:799-809

7. Kubica M, Guzik K, Koziel J, Zarebski M, Richter W, Gajkowska B, Golda A, Maciąg-Gudowska A, Brix K, Foster T, Potempa J (2008) A potential new pathway for Staphylococcus aureus dissemination: the silent survival of 
$\mathrm{S}$ aureus phagocytosed by human monocyte-derived macrophages. PLoS ONE 3(1):e1409

8. Speziale P, Pietrocola G, Foster TJ, Geoghegan JA (2014) Protein-based biofilm matrices in staphylococci. Fron Cell Infect Microbiol 4:171. https://doi.org/10.3389/fcimb.2014. 00171

9. Arciola CA, Baldassarri L, Montanaro L (2001) Presence of icaA and icaD genes and slime production in a collection of staphylococcal strains from catheter-associated infections. J Clin Microbiol 39:2151-2156

10. Arciola CR, Campoccia D, Ravaioli S, Montanaro L (2015) Polysaccharide intercellular adhesion in biofilm: structural and regulatory aspects. Front Cell Infect Microbiol. https:// doi.org/10.3389/fcimb.2015.00007

11. Sabate Bresco M, Harris LG, Thompson K, Stanic B, Morgenstern M, O’Mahony L, Richards RG, Moriarty TF (2017) Pathogenic mechanisms and host interactions in Staphylococcus epidermidis device-related infection. Front. Microbiol. 8:1401

12. Otto M (2009) Staphylococcus epidermidis - the "accidental" pathogen. Nat. Rev. Microbiol. 7(8):555-567

13. McKenney D, Pouliot KL, Wang Y, Murthy V, Ulrich M, Döring G, Lee JC, Goldmann DA, Pier GB (1999) Broadly protective vaccine for Staphylococcus aureus based on an in vivo-expressed antigen. Science 284:1523-1527

14. Christensen GD, Simpson WA, Jounger JJ, Baddour LM, Barrett FF, Melton DM, Beachey EH (1985) Adherence of coagulase-negative staphylococci to plastic tissue culture plates: a quantitative model for the adherence of staphylococci to medical devices. J Clin Microbiol 22(6):996-1006

15. Zaidi T, Zaidi T, Yoong P, Pier GB (2013) Staphylococcus aureus corneal infections: effect of the Panton-Valentine Leucocidin (PVL) and antibody to PVL on virulence and pathology. Invest Opthalmol Vis Sci 54:4430-4438

16. Bur S, Preissner KT, Hermann M, Bischoff M (2013) The Staphylococcus aureus extracellular adherence protein promotes bacterial internalization by keratinocytes independent of fibronectin-binding proteins. J Invest Dermatol 133:2004-2012

17. Josse J, Laurent F, Diot A (2017) Staphylococcal adhesion and host cell invasion: fibronectin-binding and other mechanisms. Front Microbiol 8:2433

18. Ziebuhr W, Krimmer V, Rachid S, Lößner I, Götz F, Hacker J (1999) A novel mechanism of phase variation of virulence in Staphylococcus epidermidis: evidence for control of the polysaccharide intercellular adhesion synthesis by alternating insertion and excision of the insertion sequence element IS256. Mol Microbiol 32:345-356

19. Piechota M, Kot B, Frankowska-Maciejewska A, Grużewska A, Woźniak-Kosek A (2018) Biofilm formation by methicillin-resistant and methicillin-sensitive Staphylococcus aureus strains from hospitalized patients in Poland. Biomed Res Int 27:4657396. https://doi.org/10.1155/2018/ 4657396

20. Figueiredo AMS, Ferreira FA, Beltrame OC, Côrtes MF (2017) The role of biofilms in persistent infections and factors involved in ica-independent biofilm development and gene regulation in Staphylococcus aureus. Crit Rev Microbiol 43(5):602-620. https://doi.org/10.1080/ 1040841X.2017.1282941

21. Rohde H, Burandt EC, Siemssen N, Frommelt L, Burdelski $\mathrm{Ch}$, Wurster S et al (2007) Polysaccharide intercellular adhesin or protein factors in biofilm accumulation of Staphylococcus epidermidis and Staphylococcus aureus isolated from prosthetic hip and knee joint infections. Biomaterials 28:1711-1720

22. Ridley RA, Douglas I, Whawell SA (2012) Differential adhesion and invasion by Staphylococcus aureus of epithelial cells derived from different anatomical sites. J Med Microbiol 61:1654-1661

23. Schlievert PM, Strandberg KL, Lin YC, Peterson ML, Leung DY (2010) Secreted virulence factor comparison between methicillin-resistant and methicillin-sensitive Staphylococcus aureus and its relevance to atopic dermatitis. J Allergy Clin Immunol 125:39-49

24. Smith K, Perez A, Ramage G, Lappin D, Gemmell CG, Lang S (2008) Biofilm formation by Scottish clinical isolates of Staphylococcus aureus. J Med Microbiol 57:1018-1023

25. Fariña N, Samudio M, Carpinelli L, Nentwich MM, de Kaspar HM (2017) Methicillin resistance and biofilm production of Staphylococcus epidermidis isolates from infectious and normal flora conjunctiva. Int Ophthalmol 37:819-825

Publisher's Note Springer Nature remains neutral with regard to jurisdictional claims in published maps and institutional affiliations. 